\title{
The Link between Seasonal Influenza and NCDs: Strategies for Improving Vaccination Coverage
}

\author{
Abraham Palache ${ }^{1,2 *}$, Julia Tainijoki-Seyer ${ }^{3}$, Téa Collins ${ }^{3}$ \\ ${ }^{1}$ Abbott, Weesp, The Netherlands \\ ${ }^{2}$ International Federation of Pharmaceutical Manufacturers \& Associations (IFPMA) - Influenza Vaccine Supply \\ Task Force (IVS), Geneva, Switzerland \\ ${ }^{3}$ World Medical Association, Ferney Voltaire, France \\ Email: ${ }^{*}$ bram.palache@abbott.com
}

Received 15 September 2014; revised 30 October 2014; accepted 15 November 2014

Copyright (C) 2014 by authors and Scientific Research Publishing Inc.

This work is licensed under the Creative Commons Attribution International License (CC BY).

http://creativecommons.org/licenses/by/4.0/

(c) (i) Open Access

\begin{abstract}
Seasonal influenza is a major public health problem globally, causing significant morbidity and mortality, especially in high-risk groups. Children and adults with underlying chronic non-communicable diseases (NCDs) are especially vulnerable to complications, hospitalizations and even death from the infection. However, the link between NCDs and influenza is frequently underestimated. Vaccination against influenza is the single most effective way to reduce this vulnerability in people living with NCDs. Irrespective vaccination rates in this group fall short of the WHO recommended target of $\mathbf{7 5 \%}$. This paper explores the relationship between seasonal influenza and NCDs and proposes strategies for increasing vaccination coverage among the target groups.
\end{abstract}

\section{Keywords}

\section{Seasonal Influenza, Vaccination Coverage, NCDs, Healthcare Workers, Health Professionals}

\section{Introduction}

Influenza is a highly contagious respiratory disease caused by influenza viruses. Some $5 \%$ - $10 \%$ of adults and $20 \%-30 \%$ of children worldwide will contract seasonal influenza annually [1]. Children and adults with underlying chronic medical conditions are particularly vulnerable to complications of the infection [2]. Other groups at increased risk of severe disease and complications from influenza include pregnant women, very young child-

${ }^{*}$ Corresponding author. 
ren (aged 6 to 23 months) and older adults (commonly persons aged >65 years). Globally, seasonal influenza results in about 5 million severe cases and 500,000 annual deaths each year [1].

Healthcare workers and nursing home staff constitute a special group at an elevated risk of both contracting and transmitting influenza to already vulnerable patients. Nosocomial infections can compromise quality of care and patient safety and result in prolonged hospital stays, microbial resistance, exacerbations of existing conditions and even deaths [3]. Furthermore, absenteeism from work and resulting working days lost can impose significant economic costs on healthcare systems [4].

The primary and most effective way to reduce the burden of the disease is seasonal vaccinations. Since the virus mutates from year to year, annual vaccinations are paramount. Maintaining high vaccination coverage is particularly important in patients with chronic non-communicable diseases, or NCDs. NCDs refer to a wide range of diseases that are chronic and progress slowly. Cardiovascular Diseases (CVDs), Cancer, Diabetes and Chronic Obstructive Pulmonary Disease (COPD) comprise the four main groups of NCDs, due to their shared risk factors (tobacco, alcohol, diet and physical activity) and their contribution to the global burden of disease. These four groups of diseases will be implied throughout the paper when NCDs are mentioned.

In 2003, the World Health Assembly recommended that countries should target people at high risk, including older adults and patients with underlying medial conditions, with the goal of attaining influenza vaccination coverage of at least $75 \%$ by 2010 [5].

It has been more than a decade since member states committed to this recommendation, but the challenge has been to translate the recommendations into action. Despite the public awareness and policy efforts made at the global and national levels, influenza vaccination coverage, particularly in high-risk populations, is universally low, and the need to make vaccines available to all those who need them is critical to prevent influenza outbreaks.

Evidence suggests that influenza control efforts focused on high-risk groups in terms of exposure and contagiousness are advantageous for the reduction of influenza burden in comparison to interventions targeting the general populations. More recent recommendations emphasize prioritizing vaccination for individuals at high risk for complications due to influenza virus infection [6].

Our background research indicates that there is abundant information on the primary prevention and control of major NCDs, but little attention has been paid to the interplay of communicable and non-communicable diseases and the targeted interventions of mutual benefit. There is sufficient data to demonstrate that, apart from the fact that some NCDs have an infectious etiology (e.g. gastric cancer, hepatocellular cancer and cervical cancer), the high burden of infectious diseases and associated chronic inflammation exacerbates risks for other NCDs as well [7].

Bearing this in mind, we investigated the link between influenza and NCDs and the potential of vaccinations against seasonal influenza as secondary prevention for NCDs. Based on the available evidence in the literature, we believe that persons living with NCDs while contracting the influenza virus may face double vulnerabilities if they are a child, elderly, pregnant, or working in health care. Hence, novel approaches are needed to design strategies that explicitly address this increased vulnerability to the influenza virus.

Therefore, the purpose of this paper is threefold: 1) to alert the global health community to the relationship between seasonal influenza and NCDs; 2) to underscore the benefits of influenza vaccination as secondary prevention for NCDs and 3) to propose strategies for increasing vaccination coverage in this special high-risk group.

\section{Link between Influenza and NCDs}

NCDs are the most important cause of premature mortality globally, accounting for 36 million (63\%) of the 57 million annual deaths [8], and will have an estimated associated cost of over $\$ 30$ trillion over the next 20 years [9]. Nearly $80 \%$ of NCD mortality takes place in low- and middle-income countries, where health systems are ill prepared to deal with the NCD burden effectively [8].

There is sufficient epidemiological evidence confirming that influenza is associated with higher rates of complications, hospitalizations and even deaths in individuals living with NCDs versus the general population. This was particularly notable during the $2009-2010 \mathrm{H} 1 \mathrm{~N} 1$ pandemic [10]. In non-pandemic years, $80 \%$ of persons hospitalized for influenza in the USA had one or more underlying medical conditions [11].

In terms of complications and hospitalizations, the probability of hospitalization for influenza is three times 
higher in diabetics than in the general population [12]. In persons with cardiovascular disease, systemic respiratory infections, which are frequently caused by influenza viruses, increase the risk of stroke and heart attacks three- and five-fold respectively, in the three days following the onset of infection [13].

The impact of influenza infection on mortality among high-risk groups is even more pronounced. In the UK, epidemiological surveillance data from 2010 to 2011 indicated that patients in a risk group due to chronic NCDs had a 10-fold greater risk of mortality due to influenza compared to patients who were not in an at-risk category [14]. In general, peak periods of mortality among NCD patients coincide with peaks of pneumonia and seasonal influenza [15]. As an example, the risk of dying from acute myocardial infarction and chronic ischaemic heart disease is 1.3 times greater during influenza epidemic weeks [16]. Case fatality rates from Influenza A can be over $30 \%$ in persons with COPD compared to $0.1 \%$ or less in the healthy population [17]. Mortality rates in NCD patients range from ten to 377 per 100,000 influenza cases, depending on the number of high-risk conditions [18].

The highest rates of influenza mortality are noted among persons aged 65 and older. For example, in the United States influenza infection was responsible for 132.5 per 100,000 person-years for all cause deaths, 98.3 for underlying respiratory and circulatory deaths and 22.1 for underlying pneumonia and influenza deaths [19]. If two comorbid conditions are present (old persons and high-risk), influenza-related death rates are 100 times greater than in healthy adults [20].

\section{Influenza Vaccination Benefits and Vaccination Coverage in High-Risk Groups}

There is sufficient evidence to demonstrate that vaccination against influenza is one of the most cost-effective public health interventions. According to WHO, vaccination can reduce influenza-related morbidity by $60 \%$ and mortality by up to $80 \%$. In addition, the indirect benefits from vaccinations may include savings in terms of reduced related healthcare costs due to reduced disease burden [1].

Vaccination against influenza is particularly beneficial for persons living with NCDs with regard to reduced mortality, hospitalizations and complications. When the impact of vaccination on NCDs was measured in over 35,000 older adults, mortality from stroke, diabetes, COPD, and heart disease was lowered by $65 \%, 55 \%, 45 \%$ and $22 \%$ respectively [21]. Other studies demonstrated that seasonal vaccination had reduced the risk of hospitalization by as much as 79\% in diabetics [22] and 54\% in persons with COPD [23]. Complications, such as heart attacks in cardiovascular or COPD patients, may be reduced by up to 67\% [23]-[26] and the chance of stroke occurrence may be reduced by $24 \%$ [27]. Exacerbations of COPD may also be reduced by vaccinations against influenza [28].

Despite all the known benefits that influenza vaccination brings, the vaccination coverage remains unacceptably low globally. There is some evidence, mostly from Europe and the United States, that seasonal influenza vaccination rates are higher in persons with NCDs than in the general population. However, they still fall short of the WHO [5] and EU [29] recommended target of 75\% vaccination coverage. For example, in the United States, only one in three adults with heart disease (34\%) received influenza vaccination in 2005 [2]. Similarly, seasonal vaccination coverage in people with chronic NCDs in five European countries in season 2006-2007 ranged from $29.8 \%$ in Germany to $59.4 \%$ in the UK [30]. Another European study noted that $50 \%$ of the unvaccinated eligible people (2 - 64 years old) were those living with NCDs [31].

Even the fear of an emerging pandemic during the 2009-2010 H1N1 outbreak, did not significantly alter influenza vaccination rates in persons with NCDs. For example, the coverage with an H1N1 vaccine in NCD groups was around 26\% in Korea [32] and in the USA [33] and only 21\% in France [34].

Vaccination uptake seems to improve with age. In France, the probability of getting vaccinated was nearly10 times higher in older adults and the chronically ill than in the group of people with chronic NCDs who were less than 65 years old [30]. While vaccine is less effective in preventing influenza in people over 65, it has been shown to significantly reduce complications and deaths in this age group [35]. For example, one Spanish study found that vaccination against influenza in older people with cardiac disease reduced the risk of winter mortality by as much as $37 \%$ during four influenza seasons [36].

Children are a high risk group requiring special attention. Currently, only a few countries recommend the influenza vaccine in healthy children. Children with NCDs, however, should be universally immunized annually. Children's vulnerability is twofold: first, they are particularly prone to complications from influenza; second, they are also the main vectors of transmitting the infection to family members, who may include older adults and 
chronically ill persons particularly vulnerable to the disease. However, the data on vaccination coverage of children is limited, and what is available is not particularly encouraging. For example, the Spanish national survey found coverage of 7\% and 6.5\% among children aged 6 - 23 months and 2 - 15 year olds, respectively [37]. Similarly, pediatric seasonal influenza vaccination has been estimated at between $31 \%-66 \%$ in Italy [38] and $12 \%$ in the United States [39].

Healthcare workers are another high-risk group in terms of both susceptibility and contagiousness: they are at a risk of exposure to influenza virus since healthcare facilities are a frequent site of nosocomial outbreaks [40]. Healthcare workers can act as vectors as well, unknowingly infecting their patients particularly when the infection is asymptomatic. In addition, they may also have underlying medical conditions, thus increasing the risk of developing a severe disease with complications. Despite the evidence of effectiveness and consistent recommendations by WHO and public health authorities for universal vaccination of healthcare workers, the vaccination coverage in this group remains low, ranging from $48 \%$ in France to $13.9 \%$ in Poland [18].

Vaccination rates of US healthcare workers are a bit higher than in Europe, but they are still below the recommended universal coverage. According to the US Centers for Disease Control and Prevention (CDC), the seasonal influenza vaccination rates among healthcare workers in 2013 were 58.9\% in the United States [41]. The data from other regions are limited, but what is available is consistent with the findings from Europe and the USA. For example, a study from Israel, which surveyed 27 primary care community health centers in Jerusalem, found that the vaccination rate was at $30.2 \%$ among healthcare workers [42]. About a third of the respondents noted that their decision not to get vaccinated had been affected by the negative attitude of the media towards vaccinations.

Another study of the factors influencing healthcare workers' uptake of influenza vaccination noted that high perceived risk for influenza infection, reduction in the risk to infect patients, knowledge of and agreement with national guidelines, social influence of people close to the respondents, media interest and the ethical perspective that all healthcare workers should get vaccinated, were important considerations whether or not to get a vaccine shot [43]. In general, higher awareness and knowledge of scientific evidence as well as positive attitude towards vaccinations are predictors of a higher vaccination uptake [44].

\section{Strategies to Improve Influenza Vaccination Rates}

Despite national and international recommendations to increase influenza vaccination coverage, particularly in high-risk groups, the coverage is still very low globally. Implementing a targeted-group strategy is complex, and a multipronged approach is needed at both global and country levels to increase vaccination rates.

\subsection{Global Level Strategy}

Need to Include Influenza Vaccinations in the Global Monitoring Framework for NCDs

At the global level, WHO has developed a Global Vaccine Action Plan and called on member states to take a "life-course" approach and "make the benefits of immunization available to all those at risk in every age group" [45]. The plan specifically mentioned the need to make influenza vaccines available (along with HPV and rabies vaccines) to individuals at "special risk". However, the definition of "high risk" is open to interpretation, and the relationship between influenza and NCDs is not explicit. Much more needs to be done to explore the link between influenza and chronic diseases and to promote vaccinations as a strategy of secondary prevention for NCDs.

The UN High Level Meeting on Non-communicable Disease Prevention and Control in September 2011 adopted a political declaration, which provided a powerful political platform to galvanize action at national and global levels against NCDs. Following the political declaration, WHO developed a Global Monitoring Framework with nine voluntary targets to accelerate action towards tackling the major risk factors and reducing premature mortality from NCDs [46]. The nine targets were then broken down into 25 indicators to measure progress. The global target of 25\% reduction in NCD deaths by 2025 was adopted by the World Health Assembly in 2012.

To achieve the WHO target of $25 \%$ reduction in preventable deaths, healthcare systems will have to provide person-centered care with improved outreach to effectively manage risk factors, identify those at high risk and provide care for illness episodes over many years. In many countries, healthcare systems are simply not pre- 
pared to address chronic diseases, their complications and multi-morbidity [47]. Secondary prevention of NCDs through vaccinations is a simple cost-effective intervention that most healthcare systems can afford immediately without any major reform efforts. The global-level commitment is essential for formulating corresponding country-level policies and programs.

The WHO Global Monitoring Framework acknowledges the role of vaccines to prevent NCDs. For example, one of the targets in the NCD Global Monitoring Framework is set at $80 \%$ coverage for essential medicines and technologies. The corresponding indicators propose increased access to Hepatitis B and Human Papilloma Virus vaccines to prevent cancer, one of the deadliest NCDs. However, there is no mention of influenza vaccinations' role to prevent unnecessary morbidity and mortality among people living with NCDs. We suggest that improved access to seasonal influenza vaccinations be added to the monitoring framework due to the vaccine's potential significant benefits in the secondary prevention for NCDs.

\subsection{Country Level Strategies}

At the country level, effective implementation of targeted vaccinations may be positively influenced by interventions that remove access barriers to the vaccine, target interventions at high-risk and high-transmitting groups and increase demand for the vaccine by improved awareness and education campaigns.

\subsubsection{Improved Access to Influenza Vaccines}

Given the seasonality of influenza vaccination, and the limited time to achieve broad vaccine delivery, one policy option would be to consider universal influenza vaccination. There are examples in the literature, when some countries have instituted universal influenza immunization programs with the aim of reducing barriers to access vaccination and increase coverage in high-risk groups that may be difficult to identify otherwise. For example, in the United States, under the Patient Protection and Affordable Care Act, individuals may receive influenza vaccines without making a copayment or meeting a deductible [48]. This universal influenza vaccination policy has significantly increased coverage among adults with NCDs by doubling the rates between 2004-2005 and 2010-2011 influenza seasons [49]. However, universal vaccination against influenza is not feasible in most countries, and focusing on high-risk groups seems to be the best alternative strategy due to its potential to prevent more unnecessary hospitalizations and premature deaths related to influenza in these particular groups.

Irrespective of strategies chosen (high-risk vs. general population), making the vaccine affordable is one of the most important factors for improving coverage in all population groups. There is evidence that when influenza vaccine provision is covered by insurance schemes, easy access to free vaccinations plays a key role in improving coverage rates. For example, a study in Hong Kong found that approximately $45 \%$ of respondents would consider getting vaccinated if influenza vaccine was provided for free [50].

\subsubsection{Vaccination of High-Risk and High Transmitting Groups}

Vaccination of high-risk groups, such as people living with NCDs, along with potentially high-transmitting groups, such as schoolchildren, can be a key to reducing influenza burden in communities. Children are particularly prone to complications due to influenza. This may be explained by higher exposure and less prior immunity when compared to adults. The infection may be particularly severe if underlying NCDs are present. It is estimated that hospitalizations due to influenza-associated cardiopulmonary conditions may exceed 288 per 10,000 in previously healthy children in the USA [4].

Studies indicate that high levels of vaccination coverage among schoolchildren could protect not only the vaccinees themselves, but their family members as well and may even reduce mortality among older individuals [51]. For example, experience from Japan suggests that $80 \%$ vaccination coverage among schoolchildren prevented an estimated 37,000 - 49,000 excess deaths per year among older adults [52]. Some authors suggest that even if $50 \%$ of children could be vaccinated, community-wide transmission could be significantly reduced [53]. Others calculated a $50 \%$ reduction of influenza cases if $20 \%$ of the study population (children aged 6 months to 18 years) were vaccinated and $95 \%$ reduction in the incidence of disease among children when vaccination coverage was $80 \%$ [54].

Strategies to increase vaccination rates among children include nationwide awareness raising campaigns among policymakers, healthcare providers, physicians and especially, parents; sending free vaccination vouchers to parents of children with NCDs (particularly asthma), and recall systems to remind individuals to get vac- 
cinated, which proved to be effective both among children and adults [54].

\subsubsection{Vaccination of Healthcare Workers}

WHO recognizes that medical professionals and the healthcare system are in a unique position to help patients with NCDs. "They play a crucial role in linking pharmacological and non-pharmacological methods for secondary prevention" [55]. Clinical settings, particularly at the Primary Healthcare (PHC) level, are also an ideal environment for both recommending and providing flu vaccines. We believe that there are many missed opportunities in clinical practice that can cumulatively contribute to the reduction of high burden of NCDs and influenza morbidity and mortality.

Influenza vaccination of healthcare workers is recommended in the United States and more than 40 countries worldwide. Since both symptomatic and asymptomatic infected healthcare workers can spread the virus, the only reliable protection is vaccination. The most recent evidence indicates that healthcare workers' vaccination against influenza reduces mortality and influenza cases in healthcare facilities [56]. Vaccine efficacy rate is about $86 \%$ when the circulating virus strain and the vaccine are well matched. The economic benefits are also well documented: a cost-benefit analysis from healthcare systems perspective found that for every $\$ 1000$ spent on vaccination of healthcare workers, $\$ 16,000$ in costs were saved mainly due to reduced staff absenteeism and reduction in lost productivity [57].

Healthcare settings are places where people with NCDs and other high-risk groups tend to congregate. Hence, annual influenza immunization of healthcare workers can prevent nosocomial infections and decrease the exposure among high-risk groups.

Surprisingly, healthcare workers show consistently low vaccination rates year after year across the globe. The United States shows a higher vaccination coverage, perhaps due to educational campaigns and frequent media reminders during the flu season. In season 2011-2012 the coverage of healthcare workers was at $63.4 \%$ [58]. Vaccination coverage is much lower in Europe and shows a wide variation from country to country. In season 2006-2007, 22.6\% of healthcare workers were vaccinated in Germany, which was almost twice as high as in Italy, where only12.2\% of healthcare workers received the vaccine [4].

Some of the barriers cited in the literature against receiving the vaccine were the lack of knowledge among healthcare professionals, restricted access to vaccination guidelines among employees working in a hospital, as well as fear of vaccines and needles and a low perception of risk [4].

Given the fact that strong recommendations from healthcare professionals about vaccinations against influenza have a significant positive effect on patients, raising vaccination coverage among this group is paramount.

Using healthcare professionals as role models can be an effective strategy to improve vaccination rates in NCD patients. The role of physicians is particularly important in this regard. A recent study from Israel provided evidence that patients whose physicians got a flu shot were more likely to follow their lead than patients of the physicians who did not get the flu shot [59].

Since NCD patients require a life-long interaction with healthcare providers, outpatient visits may be a perfect, but frequently missed, opportunity to identify those at high risk and provide vaccines during the influenza season. In a study in the USA, only $46 \%$ of high-risk persons reported receipt of the influenza vaccine [60]. Another study found that in a group of over 65 adults who visited their physicians 5 or more times over the previous 12 months, only $69 \%$ of whites and $44 \%$ of blacks received the vaccine [61]. In addition to very low coverage, these findings also point to significant racial/ethnic disparities. Creative strategies are needed to target disadvantaged high-risk groups.

One of the strategies to increase influenza vaccination coverage in NCD patients is to administer vaccinations to patients with chronic diseases when they make visits to specialist physicians. For example, one study suggests that an effective way to vaccinate nonelderly adults with heart conditions is to have influenza vaccines available in their offices and administer them during patient visits for cardiovascular care [2].

Hence, even though there are opportunities to promote health and prevent disease by vaccinations in nonclinical settings, such as schools and workplaces, the primary objectives of these institutions are not health-related. Studies indicate that recommendations by physicians is the most effective strategy influencing patients' behavior, since the majority of people view their doctors as the most trusted source of health information [42].

Strategies to improve vaccination rates in clinical settings focus on improving vaccine access, increasing demand, and overcoming practice-related barriers, as summarized in Table 1. 
Table 1. Strategies to increase the reach of influenza vaccination.

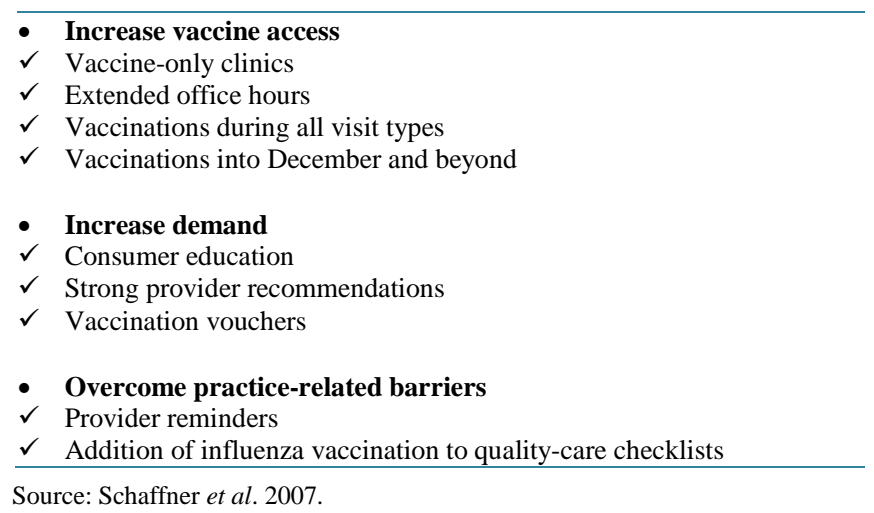

\section{Awareness Raising among High-Risk Groups: World Medical Association's Influenza Immunization Campaign}

Influenza vaccination campaigns based on educational interventions influence individuals’ decision to get vaccinated when they understand the risks associated with influenza and are motivated to protect themselves against the infection [30]. Palache, 2011 [62] found that wide-reaching communication campaigns were strongly associated with increased influenza immunization coverage.

In the United States, the US CDC conducts an annual awareness campaign, which includes advertisements, public service announcements and a broad range of free communication materials in a variety of formats (e.g. posters, information sheets, web tools and audio/visual materials) targeted at a range of risk groups [63]. In Brazil, a national campaign provides resources, including radio segments, video adverts, posters and artwork for promotional T-shirts and baseball caps [64].

Ompad et al., 2006, [65] found that multicomponent programs were the most successful at vaccinating highrisk individuals. Other studies evaluated vaccination interventions using a variety of approaches. Some used mailing to target the high-risk populations in combination with an educational insert or a brochure [66] or a media campaign [67]. Letters alone increased coverage by 5.33\% in comparison to the control group [68]. Others reported strategies to increase coverage among high-risk groups ranging from advertising, provider and patient mailings, registry-based telephone calls and patient and healthcare workers education to targeting needle exchange customers and nurses [66] [69]-[72].

An efficient method to increase coverage among high-risk individuals reported in the literature is to target venues frequented by high-risk groups, such as primary and tertiary care settings situated in hospitals or in clinics and physician practices [65]. This is particularly important for NCD patients, who tend to visit clinics more frequently. However, in today's disease-centered health systems, opportunities for NCD prevention in clinical settings may be missing. Given the fact that personal recommendation by a healthcare professional, particularly a family doctor, is the single factor most likely to encourage vaccination, using physicians as role models of healthy behaviors can be an effective approach to improve vaccination uptake among NCD patients [73].

Healthcare workers' attitudes and beliefs around influenza vaccination are important determinants of vaccine uptake, therefore vaccination awareness campaigns targeting healthcare workers are necessary. This approach is particularly encouraged in North America and Europe.

The US Healthcare Infectious Control Practices Advisory Committee and the Advisory Committee on Immunization Practices recommended that all healthcare organizations use evidence-based approaches in their campaigns and suggested five categories of components for running successful immunization campaigns among healthcare workers (Table 2).

A systematic review of seasonal influenza vaccination campaigns for healthcare workers in the United States found that campaigns with a combination of education or promotion and improved access to the vaccine yielded greater increases in coverage rates [74].

The World Medical Associations (WMA) Influenza Immunization Campaign, supported by the International Federation of Pharmaceutical Manufacturers and Associations (IFPMA), provides an example of a successful multicomponent global campaign. The campaign uses a combination of education/promotion and role models to 
Table 2. Components of influenza vaccination campaigns to improve uptake of vaccine by healthcare workers.

\begin{tabular}{|c|c|c|}
\hline Component & Operational definition & Examples \\
\hline Education or promotion & $\begin{array}{l}\text { Organized effort to raise awareness and/or } \\
\text { increase knowledge about influenza and } \\
\text { influenza vaccination }\end{array}$ & $\begin{array}{l}\text { Educational sessions and materials, materials or events } \\
\text { promoting vaccine, incentives }\end{array}$ \\
\hline Improved access to vaccine & $\begin{array}{l}\text { Strategies to allow for easier access to } \\
\text { vaccination for healthcare workers }\end{array}$ & $\begin{array}{l}\text { Mobile vaccine carts, peer-to-peer vaccination, additional } \\
\text { or extended vaccine clinics }\end{array}$ \\
\hline Legislation or regulation & $\begin{array}{l}\text { Interventions involving changes in } \\
\text { vaccination policy for healthcare workers }\end{array}$ & $\begin{array}{l}\text { Staff vaccination policy, mandatory vaccination programs, } \\
\text { declination forms }\end{array}$ \\
\hline Measurement and feedback & $\begin{array}{l}\text { Tracking of vaccination rates of healthcare } \\
\text { workers and dissemination of results }\end{array}$ & $\begin{array}{l}\text { Regular monitoring of vaccination coverage rates, reporting } \\
\text { of coverage rates to administrators and healthcare personnel }\end{array}$ \\
\hline Role models & $\begin{array}{l}\text { Activities that involve leaders and/or senior } \\
\text { staff to encourage vaccination }\end{array}$ & $\begin{array}{l}\text { Vaccination advocates and champions, public support from } \\
\text { leaders, visible vaccination of senior staff }\end{array}$ \\
\hline
\end{tabular}

Source: [74].

raise awareness of the importance of influenza immunizations among physicians and encourages them to set examples by getting vaccinated annually to protect themselves and their patients.

The WMA campaign is in its second phase, which focuses on indirect protection of patients in high-risk groups through physician vaccinations and counseling. The focus of the campaign is aligned with person-centered medicine, which stresses scientific and ethical considerations for promoting clinical care of the person (the total health of the person not just one condition), for the person (to achieve the best possible outcomes), by the person (doctors acting as role models for adopting healthy behaviors) and with the person (physician and patient working together as a team to reach the desired health goals) [75].

The WMA Campaign is global, and its success in terms of increasing vaccination coverage rates among physicians and, indirectly, of their patients, may not be possible to measure. However, the campaign encourages the work of national member associations to promote influenza vaccinations and provides resources for national immunization programs helping translate the global-level commitment into country-level action, where the impact of increased vaccination coverage will be more visible.

\section{Conclusions}

Improving influenza vaccination coverage among people living with NCDs is a complex task, and multiple strategies are needed at global and country levels to achieve the goal of 75\% vaccination rate among this group.

At the global level, it is critical to include influenza immunization as part of the monitoring framework for NCDs and underscore the vaccine's importance in secondary prevention of these diseases.

At the country level, strategies should target not only those at high risk of influenza complications, such as NCD patients, but also those at elevated risk of both contracting and transmitting the virus, such as schoolchildren and healthcare workers.

The general lack of awareness by healthcare workers and particularly clinicians of the explicit relationship between influenza vaccinations and NCD management may be an important impeding factor in vaccination uptake among the vulnerable groups, especially people living with NCDs. Therefore, awareness building campaigns with a strong educational component is key to a better compliance of healthcare workers with current influenza vaccination recommendations.

To design effective vaccination programs globally, more data are needed on the epidemiology of the disease and vaccine uptake rates in vulnerable groups from low- and middle-income countries. What is currently available, comes mainly from countries in Europe and North America and is not sufficient to design strategies that are appropriate for countries’ level of development, resources available for healthcare systems, and historically established immunization practices.

More studies are needed as well to examine socioeconomic status and vaccination uptake. There is a substantial gap in the literature with respect to reporting vaccination coverage by race/ethnicity and socioeconomic status even in North America and Europe. Given the fact that NCDs are on the rise in low- and middle-income countries and tend to concentrate in poorer populations, documenting disparities in vaccination is critical to address NCDs. 
Routine surveillance of influenza manifestation and effectiveness of influenza vaccination among people with NCDs and other high risk groups should be performed and shared across all countries to improve vaccine development and coverage rates.

Global and local influenza information and education campaigns targeting the high-risk groups, including healthcare workers, is an effective strategy and should be explored around the world. However, a one-size-fitsall approach would not work. More research is needed to determine the appropriate design and components of influenza vaccination campaigns to make them context-specific and impactful.

\section{Acknowledgements}

We thank Dr Mukesh Haikerwal, Chair of the WMA Council, for reading the manuscript and providing his expert advice. Our thanks are also extended to Shawn Gilchrist, President of Gilchrist Consulting Services, Inc. who contributed to the development of the manuscript and provided background specialist research. We are also grateful to Ms Marie-Cecile Levant for her valuable comments on the early drafts of the manuscript.

\section{References}

[1] World Health Organization (2014) Influenza Fact Sheet No. 211. http://www.who.int/mediacentre/factsheets/fs211/en/

[2] Davis, M.M., Taubert, K., Benin, A.L., Brown, D.W., Mensah, G.A., Baddour, L.M. Dunbar, S. and Krumholz, H.M. (2006) Influenza Vaccination as Secondary Prevention for Cardiovascular Disease. A Science Advisory from the American Heart Association/American College of Cardiology. Journal of the American College of Cardiology, 48, 1498-1502. http://dx.doi.org/10.1016/j.jacc.2006.09.004

[3] Hollmeyer, H., Hayden, F., Poland, G. and Buchholz, U. (2009) Influenza Vaccination of Healthcare Workers in Hospitals-A Review of Studies on Attitudes and Predictors. Vaccine, 27, 3935-3944. http://dx.doi.org/10.1016/j.vaccine.2009.03.056

[4] Blank, P.R. and Szucs, T.D. (2009) Increasing Influenza Vaccination Coverage in Recommended Population Groups in Europe. Expert Review of Vaccines, 8, 425-433. http://dx.doi.org/10.1586/erv.09.7

[5] World Health Organization (2003) Prevention and Control of Influenza Pandemics and Annual Epidemics. Fifty-Sixth World Health Assembly. WHA56.19. http://apps.who.int/gb/archive/pdf_files/WHA56/ea56r19.pdf

[6] Harper, S.A., Fukuda, K., Uyeki, T.M., Cox, N.J. and Bridges, C.B. (2005) Prevention and Control of Influenza. Recommendations of the Advisory Committee on Immunization Practices (ACIP). Morbidity and Mortality Weekly Report, 54, 1-40.

[7] Ebrahim, S., Pearce, N., Smeeth, L., Casas, J.P., Jaffar, S. and Piot, P. (2013) Tackling Non-Communicable Diseases in Low- and Middle-Income Countries: Is the Evidence from High-Income Countries All We Need? PLoS Medicine, 10. http://www.plosmedicine.org/article/info\%3Adoi\%2F10.1371\%2Fjournal.pmed.1001377

[8] World Health Organization (2011) Global Status Report on Noncommunicable Diseases 2010-Description of the Global Burden of NCDs, Their Risk Factors and Determinants. Chapter 1: Burden: Mortality, Morbidity and Risk Factors. http://www.who.int/nmh/publications/ncd_report_chapter1.pdf

[9] Bloom, D.E., Cafiero, E.T., Jané-Llopis, E., Abrahams-Gessel, S., Bloom, L.R., Fathima, S., Feigl, A.B., Gaziano, T., Mowafi, M., Pandya, A., Prettner, K., Rosenberg, L., Seligman, B., Stein, A.Z. and Weinstein, C. (2011) The Global Economic Burden of Noncommunicable Diseases. Geneva: World Economic Forum. http://www3.weforum.org/docs/WEF_Harvard_HE_GlobalEconomicBurdenNonCommunicableDiseases_2011.pdf

[10] Fajardo-Dolci, G., Gutierrez-Vega, R., Arboleya-Casanova, H., Villalobos, A., Wilson, K.S., García, S.G., Sotelo, J., Córdova Villalobos, J.A. and Díaz-Olavarrieta, C. (2010) Clinical Characteristic of Fatalities Due to Influenza A (H1N1) Virus in Mexico. Thorax, 65, 505-509. http://dx.doi.org/10.1136/thx.2009.126953

[11] Dao, C.N., Kamimoto, L., Nowell, M., Reingold, A., Gershman, K., Meek, J., Arnold, K.E., Farley, M., Ryan, P., Lynfield, R., Morin, C., Baumbach, J., Hancock, E., Zansky, S., Bennett, N.M., Thomas, A., Vandermeer, M., Kirschke, D.L., Schaffner, W. and Finelli, L., Emerging Infections Program Network (2010) Emerging Infections Program Network. Adult Hospitalizations for Laboratory-Positive Influenza during the 2005-2006 through 2007-2008 Seasons in the United States. The Journal of Infectious Diseases, 202, 881-888. http://dx.doi.org/10.1086/655904

[12] US Centers for Disease Control and Prevention (2014) Diabetes Public Health Resource. Protect Yourself from Influenza (the Flu). http://www.cdc.gov/diabetes/news/docs/flu_protect.htm

[13] Smeeth, L., Thomas, S.L., Hall, A.J., Hubbard, R., Farrington, P. and Vallance, P. (2004) Risk of Myocardial Infarction and Stroke after Acute Infection or Vaccination. The New England Journal of Medicine, 351, 2611-2618. http://dx.doi.org/10.1056/NEJMoa041747

[14] UK Health Protection Agency (2011) Surveillance of Influenza and Other Respiratory Viruses in the UK 2010/2011. 
London.

[15] Reichert, T.A., Simonsen, L., Sharma, A., Pardo, S.A., Fedson, D.S. and Miller, M.A. (2004) Influenza and the Winter Increase in Mortality in the United States, 1959-1999. American Journal of Epidemiology, 160, 492-502. http://dx.doi.org/10.1093/aje/kwh227

[16] Madjid, M., Miller, C.C., Zarubaev, V.V., Marinich, I.G., Kiselev, O.I., Lobzin, Y.V., Filippov, A.E. and Casscells, S.W. (2007) Influenza Epidemics and Acute Respiratory Disease Activity Are Associated with a Surge in Autopsy-Confirmed Coronary Heart Disease Death: Results from 8 Years of Autopsies in 34,892 Subjects. European Heart Journal, 28, 1205-1210. http://dx.doi.org/10.1093/eurheartj/ehm035

[17] Plans-Rubio, P. (2007) Prevention and Control of Influenza in Persons with Chronic Obstructive Pulmonary Disease. International Journal of Chronic Obstructive Pulmonary Disease, 2, 41-53. http://dx.doi.org/10.2147/copd.2007.2.1.41

[18] Blank, P.R. and Szucs, T.D. (2009) Increasing Influenza Vaccination Coverage in Recommended Population Groups in Europe. Expert Review of Vaccines, 8, 425-433. http://dx.doi.org/10.1586/erv.09.7

[19] Thomson, W.W., Shay, D.K., Weintraub, E., Brammer, L., Cox, N., Anderson, L.J. and Fukuda, K. (2003) Mortality Associated with Influenza and Respiratory Syncytial Virus in the United States. Journal of the American Medical Association, 289, 179-186. http://dx.doi.org/10.1001/jama.289.2.179

[20] Barker, W.H. and Mullooly, J.P. (1982) Pneumonia and Influenza Deaths during Epidemics: Implications for Prevention. Archives of Internal Medicine, 142, 85-89. http://dx.doi.org/10.1001/archinte.1982.00340140087016

[21] Wang, C.S., Wang, S.T., Lai, C.T., Lin, L.J. and Chou, P. (2007) Impact of Influenza Vaccination on Major Cause-Specific Mortality. Vaccine, 25, 1196-1203. http://dx.doi.org/10.1016/j.vaccine.2006.10.015

[22] Colquhoun, A.J. (1997) Effectiveness of Influenza Vaccine in Reducing Hospital Admissions in People with Diabetes. Epidemiology and Infection, 119, 335-341. http://dx.doi.org/10.1017/S095026889700825X

[23] Sung, L.C., Chen, C.I., Fang, Y.A., Lai, C.H., Hsu, Y.P., Cheng, T.H., Miser, J.S. and Liu, J.C. (2014) Influenza Vaccination Reduces Hospitalization for Acute Coronary Syndrome in Elderly Patients with Chronic Obstructive Pulmonary Disease: A Population-Based Cohort Study. Vaccine, 32, 3843-3849. http://dx.doi.org/10.1016/j.vaccine.2014.04.064

[24] Macintyre, C.R., Heywood, A.E., Kovoor, P., Ridda, I., Seale, H., Tan, T., Gao, Z., Katelaris, A.L., Siu, H.W., Lo, V., Lindley, R. and Dwyer, D.E. (2013) Ischaemic Heart Disease, Influenza and Influenza Vaccination: A Prospective Case Control Study. Heart, 99, 1843-1848. http://dx.doi.org/10.1136/heartjnl-2013-304320

[25] Naghavi, M., Barlas, Z., Siadaty, S., Naguib, S., Madjid, M. and Casscells, W. (2000) Association of Influenza Vaccination and Reduced Risk of Recurrent Myocardial Infarction. Circulation, 102, 3039-3045. http://dx.doi.org/10.1161/01.CIR.102.25.3039

[26] Udell, J.A., Zawi, R., Bhatt, D.L., Keshtkar-Jahromi, M., Gaughran, F., Phrommintikul, A., Ciszewski, A., Vakili, H., Hoffman, E.B., Farkouh, M.E. and Cannon, C.P. (2013) Association between Influenza Vaccination and Cardiovascular Outcomes in High-Risk Patients. A Meta-Analysis. Journal of the American Medical Association, 310, 1711-1720. http://dx.doi.org/10.1001/jama.2013.279206

[27] Siriwardena, A.N., Asghar, Z. and Coupland, C.C. (2014) Influenza and Pneumoccocal Vaccination and Risk of Stroke or Transient Ischaemic Attack-Matched Case Control Study. Vaccine, 32, 1354-1361. http://dx.doi.org/10.1016/j.vaccine.2014.01.029

[28] Varkey, J.B., Varkey, A.B. and Varkey, B. (2009) Prophylactic Vaccinations in Chronic Obstructive Pulmonary Disease: Current Status. Current Opinion in Pulmonary Medicine, 15, 90-99. http://dx.doi.org/10.1097/MCP.0b013e3283218356

[29] The Council of the European Union (2009) Council Recommendation of 22 December 2009 on Seasonal Influenza Vaccination. http://eurlex.europa.eu/LexUriServ/LexUriServ.do?uri=OJ:L:2009:348:0071:0072:EN:PDF

[30] Blank, P.R., Schwenkglenks, M. and Szucs, T.D. (2008) Influenza Vaccination Coverage Rates in Five European Countries during Season 2006/07 and Trends over Six Consecutive Seasons. BMC Public Health, 8, 272. http://dx.doi.org/10.1186/1471-2458-8-272

[31] Preaud, E., Durand, L., Macabeo, B., Farkas, N., Sloesen, B., Palache, A., Shupo, F. and Samson, S.I., the Vaccines Europe Influenza Working Group (2014) Annual Public Health and Economic Benefits of Seasonal Influenza Vaccination: A European Estimate. BMC Public Health, 14, 813. http://dx.doi.org/10.1186/1471-2458-14-813

[32] Heo, J.Y., Chang, S.H., Go, M.J., Kim, Y.M., Gu, S.H. and Chun, B.C. (2013) Risk Perception, Preventive Behaviors, and Vaccination Coverage in the Korean Population during the 2009-2010 Pandemic Influenza A (H1N1): Comparison between High-Risk Group and Non-High-Risk Group. PLoS ONE, 8, e64230.

[33] Lu, P.J., Gonzalez-Feliciano, A., Ding, H., Bryan, L.N., Yankey, D., Monsell, E.A., Greby, S.M. and Euler, G.L. (2013) Influenza A (H1N1) 2009 Monovalent and Seasonal Influenza Vaccination among Adults 25 to 64 Years of Age with High-Risk Conditions-United States, 2010. American Journal of Infection Control, 41, 702-709. 
http://dx.doi.org/10.1016/j.ajic.2012.10.027

[34] Privileggio, L., Falchi, A., Grisoni, M.L., Souty, C., Turbelin, C., Fonteneau, L., Hanslik, T. and Kernéis, S. (2013) Rates of Immunization against Pandemic and Seasonal Influenza in Persons at High Risk of Severe Influenza Illness: A Cross-Sectional Study among Patients of the French Sentinelles General Practitioners. BMC Public Health, $13,246$. http://dx.doi.org/10.1186/1471-2458-13-246

[35] Simonsen, L., Reichert, T.A., Viboud, C., Backwelder, W.C., Talor, R.J. and Miller, M.A. (2005) Impact of Influenza Vaccination on Seasonal Mortality in the US Elderly Population. Archives of Internal Medicine, 165, 265-272. http://dx.doi.org/10.1001/archinte.165.3.265

[36] De Diego, C., Vila-Cocroles, A., Ochoa, O., Rodriguez-Blanco, T., Salsench, E., Hospital, I., Bejarano, F., Del Puy Muniain, M., Fortin, M. and Canals, M., EPIVAC Study Group (2008) Effects of Annual Influenza Vaccination on Winter Mortality in Elderly People with Chronic Heart Disease. European Heart Journal, 30, 209-216. http://dx.doi.org/10.1093/eurheartj/ehn498

[37] Jiménez-García, R., Hernández-Barrera, V., Carrasco-Garrido, P., López de Andrés, A., Pérez, N. and de Miguel, A.G. (2008) Influenza Vaccination Coverages among Children, Adults, Health Care Workers and Immigrants in Spain: Related Factors and Trends, 2003-2006. Journal of Infection, 57, 472-480. http://dx.doi.org/10.1016/j.jinf.2008.10.005

[38] Zoppi, G. and Trucchi, C. (2011) Investigation on Seasonal Influenza Vaccination among Children with High-Risk Medical Conditions Who Live in the Area of Local Health Agency 4 “Chiavarese”. Journal of Preventive Medicine and Hygiene, 52, 148-150.

[39] Cho, B.H., Kolasa, M.S. and Messonnier, M.L. (2008) Influenza Vaccination Coverage Rate among High-Risk Children during the 2002-2003 Influenza Season. American Journal of Infection Control, 36, 582-587. http://dx.doi.org/10.1016/j.ajic.2007.09.013

[40] Poland, G., Tosh, T. and Jacobson, R.M. (2005) Requiring Influenza Vaccination for Healthcare Workers: Seven Truths We Must Accept. Vaccine, 23, 2251-2255. http://dx.doi.org/10.1016/j.vaccine.2005.01.043

[41] US Centers from Disease Control and Prevention (2014) Flu Vaccination Coverage in the United States, Influenza Season 2013-2014. http://www.cdc.gov/flu/fluvaxview/coverage-1314estimates.htm

[42] Abramson, H.Z. and Levi, O. (2008) Influenza Vaccination among Primary Healthcare Workers. Vaccine, 28, 24822489. http://dx.doi.org/10.1016/j.vaccine.2008.03.011

[43] Kramarz, P., Ciancio, B. and Nicoll, A. (2009) Seasonal and Pandemic Influenza Vaccines for the Elderly and Other Risk Groups. Polskie Archiwum Medycyny Wewnetrznej, 119, 654-659.

[44] Herzog, R., Álvarez-Pasquin, M.J., Díaz, C., Del Barrio, J.L., Estrada, J.M. and Gil, Á. (2013) Are Healthcare Workers’ Intentions to Vaccinate Related to Their Knowledge, Beliefs and Attitudes? A Systematic Review. BMC Public Health, 13, 154. http://dx.doi.org/10.1186/1471-2458-13-154

[45] World Health Organization (2013) Global Vaccine Action Plan 2011-2020. WHO, Geneva.

[46] World Health Organization (2014) NCD Global Monitoring Framework: Targets and Indicators. http://www.who.int/nmh/global_monitoring_framework/en/

[47] Atun, R., Jaffar, S., Nishtar, S., Knaul, F.M., Barreto, M.L., Nyirenda, M., Banatvala, N. and Piot, P. (2013) Improving Responsiveness of Health Systems to Non-Communicable Diseases. The Lancet, 381, 690-697. http://dx.doi.org/10.1016/S0140-6736(13)60063-X

[48] US Department of Health and Human Services (2014) Preventive Services Covered under the Affordable Care Act. http://www.hhs.gov/healthcare/facts/factsheets/2010/07/preventive-services-list.html

[49] Glezen, W.P. (2009) Benefits of a Universal Influenza Immunization Program: More Than the Reduction in the Use of Antibiotics. Clinical Infectious Diseases, 49, 757-758. http://dx.doi.org/10.1086/605088

[50] Lau, J.T., Yeung, N.C., Choi, K.C., Cheng, M.Y., Tsui, H.Y. and Griffiths, S. (2009) Acceptability of A/H1N1 Vaccination during Pandemic Phase of Influenza A/H1N1 in Hong Kong: Population Based Cross Sectional Survey. BMJ, 339, b4164. http://dx.doi.org/10.1136/bmj.b4164

[51] Reichert, T.A., Sugaya, N., Fedson, D.S., Glezen, W.P., Simonsen, L. and Tashiro, M. (2001) The Japanese Experience Vaccinating Schoolchildren against Influenza. The New England Journal of Medicine, 344, 889-896. http://dx.doi.org/10.1056/NEJM200103223441204

[52] Drummond, M., Chevat, C. and Lothgren, M. (2007) Do We Fully Understand the Economic Value of Vaccines? Vaccines, 25, 5945-5957. http://dx.doi.org/10.1016/j.vaccine.2007.04.070

[53] Mereckiene, J., Cotter, S., Weber, J.T., Nicoll, A., Lévy-Bruhl, D., Ferro, A., Tridente, G., Zanoni, G., Berra, P., Salmaso, S. and O'Flanagan, D., the VENICE Gatekeepers Group (2008) Low Coverage of Seasonal Influenza Vaccination in the Elderly in Many European Countries. Eurosurveillance, 13.

[54] Weycker, D., Edelsberg, J., Halloran, M.E., Longini Jr., I.M., Nizam, A., Ciuryla, V. and Oster, G. (2005) Popula- 
tion-Wide Benefits of Routine Vaccination of Children against Influenza. Vaccine, 23, 1284-1293. http://dx.doi.org/10.1016/j.vaccine.2004.08.044

[55] World Health Organization (2002) Secondary Prevention of Non-Communicable Diseases in Low- and Middle-Income Countries through Community-Based and Health Service Interventions. Report of WHO-Wellcome Trust Meeting of Experts. Hinxton, Cambridge. http://whqlibdoc.who.int/hq/2002/WHO_MPN_CVD_2002.01.pdf?ua=1.

[56] Ahmed, F., Lindley, M.C., Allred, N., Weinbaum, C.M. and Grohskopf, L. (2014) Effect of Influenza Vaccination of Healthcare Personnel on Morbidity and Mortality among Patients: Systematic Review and Grading of Evidence. Clinical Infectious Diseases, 58, 50-57. http://dx.doi.org/10.1093/cid/cit580

[57] Flegel, K. (2012) Healthcare Workers Must Protect Patients from Influenza by Taking the Annual Vaccine. Canadian Medical Association Journal, 184, 1873. http://dx.doi.org/10.1503/cmaj.121679

[58] US Centers for Disease Control and Prevention (2013) Health Care Personnel Flu Vaccination, Internet Panel Survey, United States, November 2012. http://www.cdc.gov/flu/fluvaxview/hcp-ips-nov2012.htm

[59] Frank, E., Dresner, Y., Shani, M. and Vinker, S. (2013) The Association between Physicians’ and Patients’ Preventive Health Practices. Canadian Medical Association Journal, 185, 649-653. http://dx.doi.org/10.1503/cmaj.121028

[60] Egede, L.E. and Zheng, D. (2003) Racial/Ethnic Differences in Influenza Vaccination Coverage in High-Risk Adults. American Journal of Public Health, 93, 2074-2078. http://dx.doi.org/10.2105/AJPH.93.12.2074

[61] Lu, P.J., Singleton, J.A., Euler, G.L., Williams, W.W. and Bridges, C.B. (2013) Seasonal Influenza Vaccination Coverage among Adult Populations in the United States, 2005-2011. American Journal of Epidemiology, 178, 1478-1487. http://dx.doi.org/10.1093/aje/kwt158

[62] Palache, A. (2011) Seasonal Influenza Vaccine Provision in 157 Countries (2004 to 2009) and the Potential Influence of National Public Health Policies. Vaccine, 29, 9459-9466. http://dx.doi.org/10.1016/j.vaccine.2011.10.030

[63] US Centers for Disease Control and Prevention (2013) CDC Influenza Awareness Campaign, Media Relations Toolkit, November 2013. http://www.cdc.gov/flu/pdf/nivw/nivw_media_toolkit_2013.pdf.

[64] Isaude.net. (2013) Vaccination Campaign against Influenza Immunizations 12.3 Million People. http://www.isaude.net/en/noticia/34599/public-health/vaccination-campaign-against-influenza-immunizations-123-mill ion-people

[65] Ompad, D., Galea, S. and Vlahov, D. (2006) Distribution of Influenza Vaccine in High-Risk Groups. Epidemiologic Reviews, 28, 54-70. http://dx.doi.org/10.1093/epirev/mxj004

[66] Smith, D.M., Zhou, X.H., Weinberger, M., Smith, F. and McDonald, R.C. (1999) Mailed Reminders for Area-Wide Influenza Immunization: A Randomized Controlled Trial. Journal of the American Geriatrics Society, 47, 1-5.

[67] Christenson, B., Lundbergh, P., Hedlund, J. and Ortqvist, A. (2001) Effects of a Large-Scale Intervention with Influenza and 23-Valent Pneumococcal Vaccines in Adults Aged 65 Years or Older: A Prospective Study. The Lancet, 357, 1008-1011. http://dx.doi.org/10.1016/S0140-6736(00)04237-9

[68] Chan, L., MacLehose, R.F. and Houck, P.M. (2002) Impact of Physician Reminders on the Use of Influenza Vaccinations: A Randomized Trial. Archives of Physical Medicine and Rehabilitation, 83, 371-375. http://dx.doi.org/10.1053/apmr.2002.29634

[69] Dalby, D.M., Sellors, J.W., Fraser, F.D., Fraser, C., van Ineveld, C. and Howard, M. (2000) Effect of Preventive Home Visits by Nurse on the Outcomes of Frail Elderly People in the Community: A Randomized Controlled Trial. Canadian Medical Association Journal, 162, 497-500.

[70] Weaver, F.M., Goldstein, B., Evans, C.T., Legro, M.W., LaVela, S., Smith, B., Miskevics, S. and Hammond, M.C. (2003) Influenza Vaccination among Veterans with Spinal Cord Injury: Part 2. Increasing Vaccination Rates. Journal of Spinal Cord Medicine, 26, 210-218.

[71] Schluter, W.W., Ralston, D.L., Delaney, R.J., Sauaia, A. and Dunn, T.R. (1999) Increasing Influenza and Pneumococcal Vaccination and Tuberculosis Screening among Residents of Colorado Long-Term Care Facilities. Evaluation \& the Health Professions, 22, 466-483. http://dx.doi.org/10.1177/01632789922034419

[72] McCaul, K.D., Johnson, R.J. and Rothman, A.J. (2002) The Effects of Framing and Action Instructions on Whether Older Adults Obtain Flu Shots. Health Psychology, 21, 624-628. http://dx.doi.org/10.1037/0278-6133.21.6.624

[73] Holm, M., Blank, P. and Szucs, T. (2007) Developments in Influenza Vaccination Coverage in England, Scotland and Wales Covering Five Consecutive Seasons from 2001 to 2006. Vaccine, 25, 7931-7938. http://dx.doi.org/10.1016/j.vaccine.2007.09.022

[74] Lam, P.P., Chambers, L.W., MacDougall, D.M. and McCarthy, A.E. (2010) Seasonal Influenza Vaccination Campaigns for Health Care Personnel: Systematic Review. Canadian Medical Association Journal, 182, E542-E548. http://dx.doi.org/10.1503/cmaj.091304

[75] Schmolke, M. and Mezzich, J. (2012) Contrasting the Essentials of Recovery Orientation and Person-Centered Care. International Journal of Person Centered Medicine, 3, 31-35. 
Scientific Research Publishing (SCIRP) is one of the largest Open Access journal publishers. It is currently publishing more than 200 open access, online, peer-reviewed journals covering a wide range of academic disciplines. SCIRP serves the worldwide academic communities and contributes to the progress and application of science with its publication.

Other selected journals from SCIRP are listed as below. Submit your manuscript to us via either submit@scirp.org or Online Submission Portal.
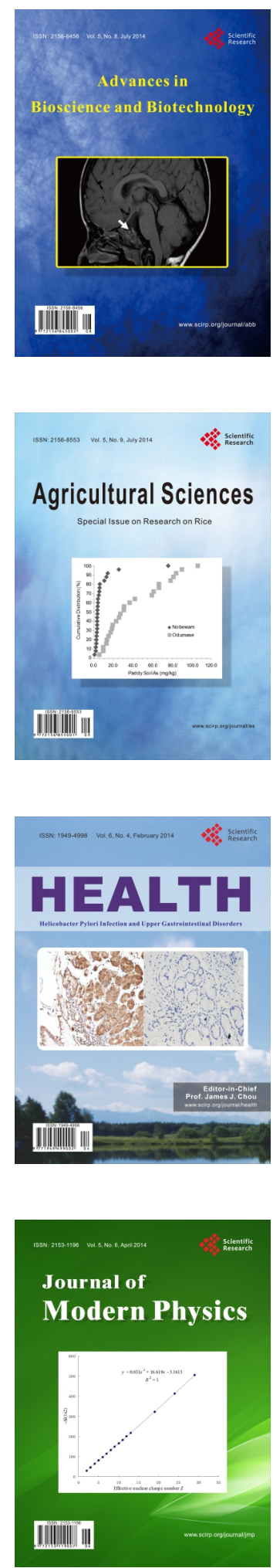
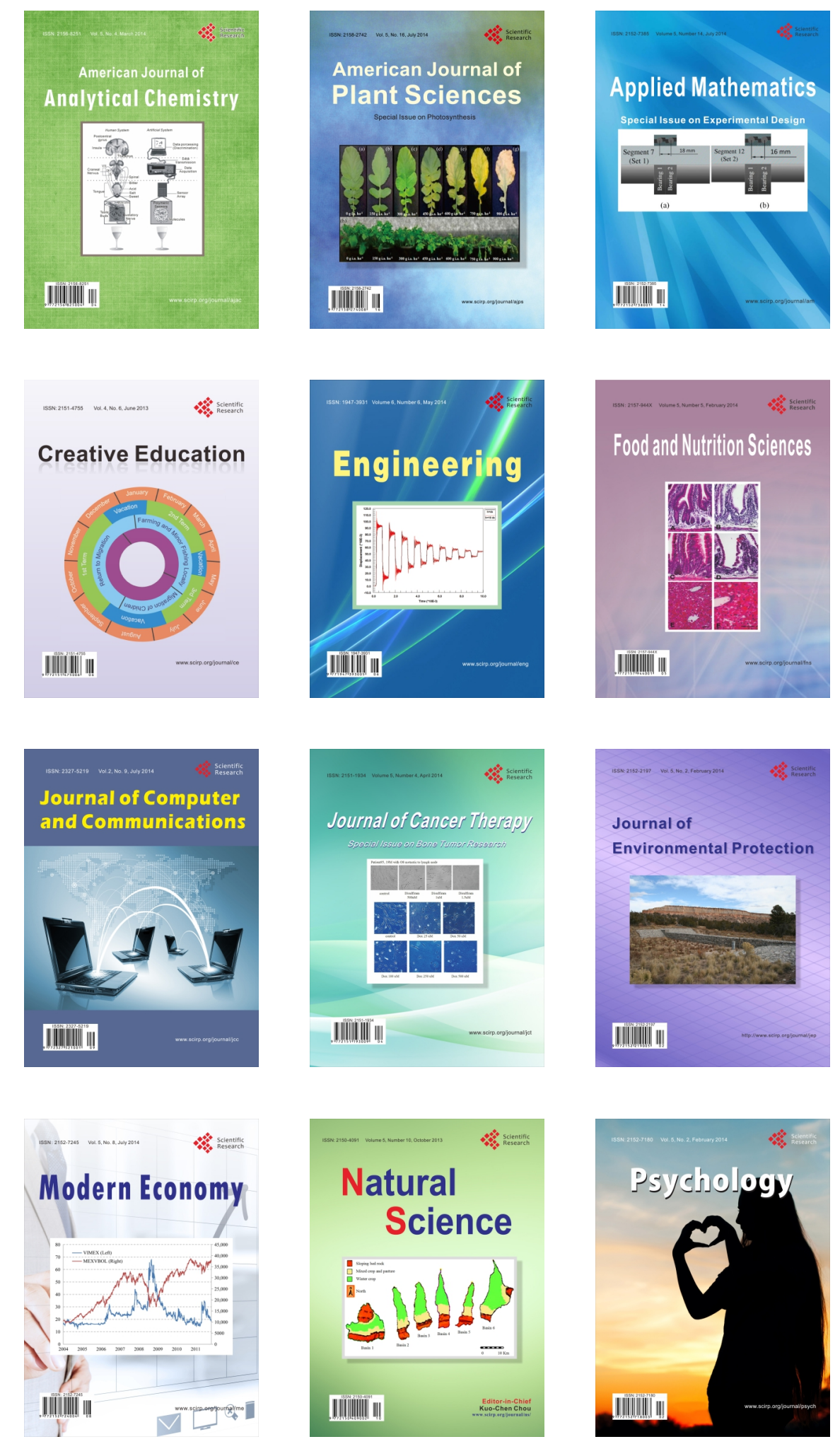